\title{
artigo
}

Ferreira, S.S.R.; Oliveira, J.V.; Souza, D.A.; Carvalho Silva, I.N.; Santos, R.C.; Andrade, S.N.; Carvalho, N.M.

Condutas no Brasil diante da pandemia de COVID-19: revisão integrativa

\section{Condutas no Brasil diante da pandemia de COVID-19; revisão integrativa}

\author{
Conduct in Brazil in face of the COVID-19 pandemic: integrative review
}

Conducta en Brazil ante la pandemia COVID-19: revisión integrativa

\begin{abstract}
RESUMO
Objetivo: Analisar as condutas definidas pelas autoridades brasileiras acerca da pandemia da COVID-19 no Brasil. Método: Trata-se de uma revisão integrativa de literatura sobre as condutas adotadas frente a pandemia da COVID-19 no Brasil. Foi realizado um levantamento de artigos nas bases de dados Medline, Lilacs e Pubmed, no período de 31 de dezembro de 2019 a 12 de abril de 2020, 19 estudos foram selecionados. Resultados: Um artigo tratou sobre as intervenções não farmacológicas, oito artigos abordaram medidas da Vigilância em Saúde e os aspectos Epidemiológicos da COVID-19 e os outros nove artigos abordaram as medidas de prevenção, tratamento e ou controle da COVID-19 no Brasil. Conclusão: A maioria das medidas tomadas pelo Brasil foi baseada em condutas adotadas em outras emergências de saúde pública com semelhanças clínicas e epidemiológicas com o atual cenário da pandemia no Brasil.
\end{abstract}

DESCRITORES: Infecções por Coronavírus; Condutas Terapêuticas; Saúde Pública.

\section{ABSTRACT}

Objective: To analyze the behaviors defined by the Brazilian authorities regarding the COVID-19 pandemic in Brazil. Method: This is an integrative literature review on the behaviors adopted in the face of the COVID-19 pandemic in Brazil. A survey of articles was carried out in the Medline, Lilacs and Pubmed databases, from December 31, 2019 to April 12, 2020, 19 studies were selected. Results: One article dealt with non-pharmacological interventions, eight articles addressed measures of Health Surveillance and the Epidemiological aspects of COVID-19 and the other nine articles addressed the measures of prevention, treatment and or control of COVID-19 in Brazil. Conclusion: Most of the measures taken by Brazil were based on conduct adopted in other public health emergencies with clinical and epidemiological similarities with the current scenario of the pandemic in Brazil. DESCRIPTORS: Coronavirus infections; Therapeutic Conduct; Public health.

\section{RESUMEN}

Objetivo: Analizar los comportamientos definidos por las autoridades brasileñas con respecto a la pandemia COVID-19 en Brasil. Método: Revisión integradora de la literatura sobre los comportamientos adoptados ante la pandemia de COVID-19 en Brasil. Se realizó una encuesta de artículos en las bases de datos Medline, Lilacs y Pubmed, del 31 de diciembre de 2019 al 12 de abril de 2020, se seleccionaron 19 estudios. Resultados: Un artículo abordó intervenciones no farmacológicas, ocho artículos abordaron medidas de Vigilancia de la Salud y los aspectos epidemiológicos de COVID-19 y los otros nueve artículos abordaron medidas de prevención, tratamiento y / o control de COVID-19 en Brasil. Conclusión: La mayoría de las medidas tomadas por Brasil se basaron en conductas adoptadas en otras emergencias de salud pública con similitudes clínicas y epidemiológicas con el escenario pandémico actual en Brasil.

DESCRIPTORES: Infecciones por coronavirus; Conducta terapéutica; Salud pública.

RECEBIDO EM: 19/08/2020 APROVADO EM: 23/09/2020

\section{Stefanie de Souza Rocha Ferreira}

Graduanda em Enfermagem, Universidade do Estado de Minas Gerais, Minas Gerais, Brasil.

ORCID: 0000-0002-0123-0559

\section{Janaina Vilela de Oliveira}

Graduanda em Enfermagem, Universidade do Estado de Minas Gerais, Minas Gerais, Brasil.

ORCID: 0000-0003-3000-6377 


\section{Danielly Araujo Souza}

Graduanda em Enfermagem, Universidade do Estado de Minas Gerais, Minas Gerais, Brasil. ORCID: 0000-0002-2194-5180

\section{Ingrid Nascimento Carvalho Silva}

Graduanda em Enfermagem, Universidade do Estado de Minas Gerais, Minas Gerais, Brasil. ORCID: 0000-0001-7038-5207

\section{Regina Consolação dos Santos}

Enfermeira. Mestre em Ciência pela Universidade Federal de São João Del Rei, Campus Centro Oeste Dona Lindu UFSJ - (CCO). Docente do Curso de Graduação em Enfermagem da Universidade do Estado de Minas Gerais (UEMG), Unidade Divinópolis. ORCID: 0000-0002-7393-3210

\section{Silmara Nunes Andrade}

Enfermeira. Doutora em Ciências da Saúde pela Universidade Federal de São João Del Rei, Campus Centro Oeste Dona Lindu UFS - (CCO). Docente do Curso de Graduação em Enfermagem da Universidade do Estado de Minas Gerais (UEMG), Unidade Divinópolis.

ORCID: 0000-0002-1975-0827

\section{Natane Moreira de Carvalho}

Enfermeira. Doutora em Patologia pela Universidade Federal de Minas Gerais. Minas Gerais, Brasil. Docente do Curso de Graduação em Enfermagem da Universidade do Estado de Minas Gerais (UEMG), Unidade Divinópolis.

ORCID: 0000-0003-1083-7640

\section{INTRODUÇÃO}

C oronavirus é uma família de vírus que possui RNA (ácido ribonucleico) de fita simples, envelopado e com alto poder de mutação, no qual acomete o sistema respiratório de seres humanos e de alguns animais. Entre 2002 e 2003, surgiu uma severa epidemia na China, denominada SARS - Síndrome Respiratória Aguda Grave (do inglês, Severe Acute Respiratory Syndrome), que apresentava taxa de letalidade em torno de $10 \%$. Já em 2012, foi registrada outra síndrome respiratória provocada também pelo Coronavírus e com taxa de letalidade, em torno de 30\%, nomeada como MERS - Síndrome Respiratória do Oriente Médio (do inglês, Moddle East Respiratory Syndrome) ${ }^{1,2}$.

Em dezembro de 2019, foi constatado o início de mais uma epidemia de SARS em Wuhan, na China. Devido à alta taxa de infecção, de susceptibilidade e de transmissão da população, principalmente através dos casos assintomáticos, a epidemia local ganhou força e acabou se espalhando por outros países ${ }^{1,3,4}$. A partir de fevereiro de 2020, o Brasil começou a registrar suas primeiras suspeitas, tendo neste mesmo mês, sua primeira ocorrência confirmada de COVID-19 - do inglês Coronavirus disease-2019 5. Presume-se que a taxa de letalidade do novo Coronavírus altere-se de acordo com cada país. No Brasil houve 10.278 pessoas infectadas e 432 mortes, entre o início da pandemia até 04 de abril de 2020. Entre pessoas que apresentam algum tipo de comorbidade, essa taxa varia em torno de $73 \%{ }^{6,2,7}$.

A transmissão da doença acontece quando um indivíduo saudável tem contato com gotículas ou secreções de outra pessoa infectada ou com objetos contaminados. Após isso ocorrer, o SARS-Cov-2 se aloja nas vias aéreas, se replica, podendo gerar sintomas específicos como: coriza, dificuldades para respirar, tosse, dores de garganta e febre, podendo levar a óbito nos casos mais graves ${ }^{8}$.

As melhores medidas que poderiam ser tomadas com o intuito de prevenir e tratar a COVID-19 seriam a vacinação e o uso de medicamentos. Porém, em virtude da recente manifestação do SARS-Cov-2, ainda não há vacinas para realizar a imunização da população mundial e nem um tratamento por meio de medicamentos que seja totalmente eficaz e recomendado desde o início da doença $9,7,4$.

Perante o que foi apresentado anterior- mente, da importância de evitar a contaminação e a transmissão da COVID-19, o presente estudo tem como propósito analisar as condutas definidas pelas autoridades brasileiras frentes a pandemia da COVID-19 no Brasil, no período entre dezembro de 2019 e maio de 2020, através de uma revisão integrativa da literatura.

\section{MÉTODO}

Trata-se de uma revisão integrativa de literatura sobre as condutas tomadas frente à pandemia da COVID-19 no Brasil.

Para conduzir a revisão integrativa considerou-se a seguinte questão: Quais são as condutas determinadas pelas autoridades brasileiras que devem ser executadas nos sistemas de saúde, instituições e pela população, frente à pandemia da $\mathrm{CO}$ VID-19 no Brasil?

Realizou-se um levantamento de artigos no período de 31 de dezembro de 2019 a 12 de abril de 2020 nas seguintes bases de dados: Literatura Latino-Americana e do Caribe em Ciências da Saúde (LILACS), Medical Literature Analysis and Retrieval Sistem on-line (Medline), ambas indexadas na Biblioteca Virtual da Saúde (BVS) e PubMed. Foram utilizados 


\section{artigo}

Ferreira, S.S.R.; Oliveira, J.V.; Souza, D.A.; Carvalho Silva, I.N.; Santos, R.C.; Andrade, S.N.; Carvalho, N.M.

Condutas no Brasil diante da pandemia de COVID-19: revisão integrativa

os seguintes descritores para a busca dos artigos científicos: "COVID-19" e "Brazil”. Sendo utilizado o operador booleano AND que fornecem a intercessão entre os descritores escolhidos.

Os critérios de inclusão definidos para a seleção dos artigos foram: todos os artigos publicados em português, inglês e espanhol que abordassem a temática "COVID-19" no Brasil. Critérios de exclusão: artigos que mencionassem a temática "COVID-19" em outros países, notas, planos de contingência, teses, livros, anais de congresso ou conferências, documentos de projetos, enfim todos documentos que não fossem do gênero textual e artigo científico.

Na primeira fase da pesquisa, foi empregado somente o termo "COVID-19" como descritor para a busca ampla de artigos nas bases de dados LILACS e MEDLINE, ambas indexadas na Biblioteca Virtual de Saúde. Obteve-se como resultado 350 trabalhos (LILACS) e 8786 trabalhos (ME-
DLINE). Após a aplicação dos seguintes filtros: base de dados (LILACS ou MEDLINE), país/ região como assunto (Brasil), tipo de documento (Artigo) e intervalo de ano de publicação (2019-2020). A busca gerou um total de 50 artigos, 10 pertencentes à LILACS e 40 a MEDLINE.

Posteriormente, realizou-se uma busca avançada no site da PubMed Central. Em uma primeira busca, utilizaram-se os descritores "COVID-19" e "Brazil", sendo essas intercedidas pelo marcador Booleano AND e pela utilização dos filtros "título" e "data de publicação (31/12/201912/05/2020)". Após esta busca, obteve-se como resultado 17 artigos. Logo em seguida, realizou-se uma segunda pesquisa na PubMed, para isto, utilizou-se os mesmos descritores e a intercessão AND entre os termos, entretanto utilizou-se agora, os filtros "resumo" e "data de publicação (31/12/2019-12/05/2020). Essa procura resultou em 17 artigos científicos.

\section{Figura 1 - Diagrama dos métodos de identificação}

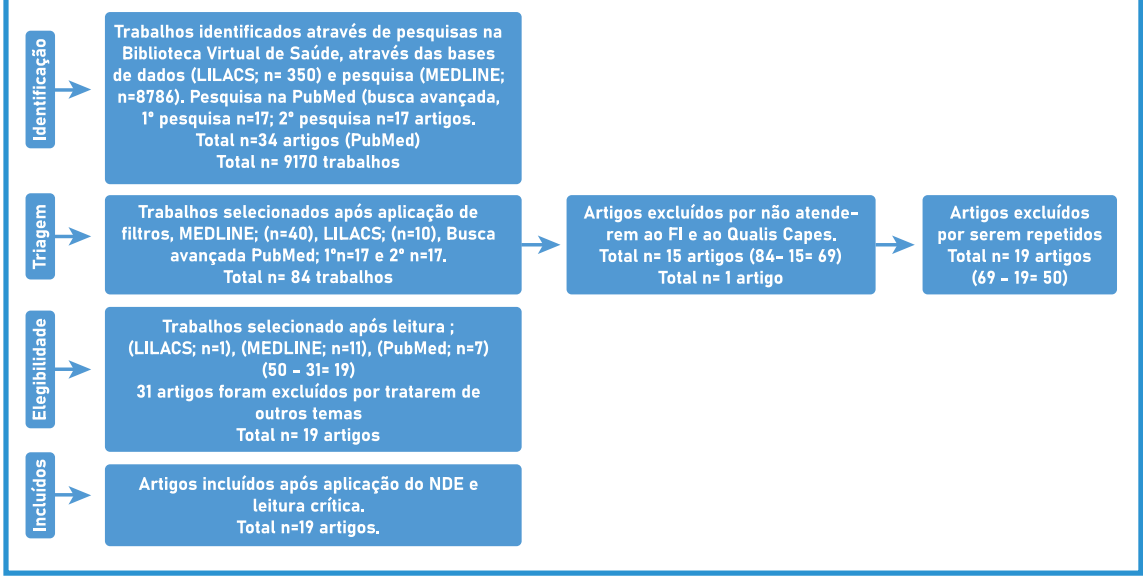

Fonte: Dados de Pesquisa, 2020.

Tabela 1 - Fator de impacto das revistas que publicaram os artigos, adaptado de Qualis CAPES, segundo a plataforma sucupira www.capes.gov.br e Nivel de evidência segundo critérios estabelecidos pela Oxford Centre for Evidence

\begin{tabular}{cccccc} 
REVISTA & CAPES & ISSN & $\begin{array}{c}\text { NIIVEL DE } \\
\text { EVIDÊNCIA }\end{array}$ & $\begin{array}{c}\text { FATOR DE } \\
\text { IMPACTO }\end{array}$ & $\begin{array}{c}\text { ÁREA DE } \\
\text { AVALIAÇÃO }\end{array}$ \\
$\begin{array}{c}\text { REVISTA BRA- } \\
\text { SILEIRA DE EPIDE- } \\
\text { MIOLOGIA }\end{array}$ & B1 & $1415-790 X$ & IIA & 0.0124 & ENFERMAGEM \\
$\begin{array}{c}\text { BRAZILIAN JOUR- } \\
\text { NAL OF OTORHI- } \\
\text { NOLARYNGOLOGY }\end{array}$ & B1 & $1808-8686$ & IA & 1,603 & ENFERMAGEM \\
\hline
\end{tabular}

Dessa forma, foram encontrados um total de 84 artigos referentes as três bases de dados, 10 da base LILACS, 40 da base MEDLINE e 34 da base PubMed.

A segunda etapa para a escolha de quais artigos entraria na análise foi composta pela avaliação dos artigos incluídos em periódicos de acordo com a classificação Qualis CAPES (Coordenação de Aperfeiçoamento de Pessoal de Nível Superior) 10 e como o fator de Impacto "impactor factor", utilizado pelas bases de dados internacionais. Foram incluídos os artigos classificados entre A1 e B2. Após esse procedimento, foram inclusos 69 artigos.

$\mathrm{Na}$ terceira fase foi realizada uma filtragem dos artigos repetidos. Assim, foram excluídos 19 artigos do total dos 69 artigos (1 pertencente a LILACS, 5 a PubMed e 13 pertencentes a MEDLINE). Dessa forma, restaram 50 artigos.

$\mathrm{Na}$ quarta e última etapa, foi realizada a leitura na integra de todos os trabalhos que restaram. Após a leitura, foram selecionados os trabalhos que abordavam exclusivamente a temática da conduta frente ao $\mathrm{CO}$ VID-19 no Brasil e que se apresentava em forma de artigos científicos. Após essa eta$\mathrm{pa}$, foram desconsiderados os documentos que não atenderam aos critérios de inclusão citados anteriormente. Dessa maneira, 31 trabalhos foram excluídos da análise, 4 (LILACS), 13 (MEDLINE) e 14(PubMed), restando 19 artigos (Figura 1).

Ressalta-se que neste estudo foi empregada uma estratégia sistemática e rigorosa para a busca dos artigos mais relevantes de acordo com a temática proposta. Contudo, como limitação, foram encontrados poucos trabalhos nacionais publicados nesse período.

A amostra final constituiu-se de 19 artigos. A partir de uma análise crítica dos trabalhos selecionados, foram verificadas as seguintes informações: ano, local de publicação, objetivos, metodologia e condutas frentes ao COVID-19 no Brasil.

\section{RESULTADOS}

Analisaram-se dezenove estudos nacionais e internacionais publicados 


\begin{tabular}{|c|c|c|c|c|c|}
\hline $\begin{array}{l}\text { CADERNOS DE } \\
\text { SAÚDE PÚBLICA }\end{array}$ & B1 & $0102-311 X$ & $\mid A /\|B /\| A$ & 0.2217 & ENFERMAGEM \\
\hline CLINICS & B1 & $1980-5322$ & IIB /IIIB & 0.0074 & ENFERMAGEM \\
\hline $\begin{array}{l}\text { EPIDEMIOLOGIA } \\
\text { E SERVIÇOS DE } \\
\text { SAÚDE }\end{array}$ & B2 & 2237-9622 & $\mid \mathrm{A} / \| \mathrm{B} / \mathrm{IA}$ & 0,1930 & ENFERMAGEM \\
\hline $\begin{array}{c}\text { REVISTA DA } \\
\text { SOCIEDADE BRA- } \\
\text { SILEIRA DE MEDI- } \\
\text { CINA TROPICAL }\end{array}$ & B1 & 0037-8682 & IIB & 1,498 & ENFERMAGEM \\
\hline $\begin{array}{c}\text { REVISTA DE SAÚ- } \\
\text { DE PÚBLICA }\end{array}$ & $\mathrm{A} 2$ & 1518-8787 & IIB & 1,968 & ENFERMAGEM \\
\hline $\begin{array}{l}\text { THE BRAZILIAN } \\
\text { JOURNAL OF } \\
\text { INFECTIOUS } \\
\text { DISEASES }\end{array}$ & B1 & $1413-8670$ & IA & 2.223 & ENFERMAGEM \\
\hline $\begin{array}{l}\text { REVISTA DO CO- } \\
\text { LEEGIO BRASILEIRO } \\
\text { DE CIRURGIÕES }\end{array}$ & B1 & $1809-4546$ & IA & 0.0272 & ENFERMAGEM \\
\hline $\begin{array}{l}\text { JOURNAL OF MI- } \\
\text { NIMALLY INVASI- } \\
\text { VE GYNECOLOGY }\end{array}$ & B1 & $1553-4650$ & IB & 2.414 & MEDICINA I \\
\hline $\begin{array}{l}\text { TRAVELL MEDICINE } \\
\text { AND INFECTIOUS } \\
\text { DISEASE }\end{array}$ & B1 & 1477-8939 & IB/IB/IB & 4.868 & $\begin{array}{c}\text { SAÚDE COLE- } \\
\text { TIVA }\end{array}$ \\
\hline $\begin{array}{l}\text { REVISTA ENFER- } \\
\text { MAGEM UERJ }\end{array}$ & B1 & 0104-3552 & IB & 0.36 & ENFERMAGEM \\
\hline
\end{tabular}

no ano de 2020, sendo um encontrado na Lilacs, onze na base de dados Medline, ambas indexadas na BVS e sete na PubMed (Tabela 2). Para maior compreensão, os artigos estudados foram apresentados em categorias, de acordo com a similaridade do assunto. A categoria um contém um artigo que discorre sobre chegada de um navio no Porto de Santos com novos casos suspeitos. A Categoria dois: possui um artigo que tratou sobre as intervenções não farmacológicas da COVID-19. A Categoria três: possui oito artigos que abordaram medidas da Vigilância em Saúde e os aspectos Epidemiológicos da COVID-19 no Brasil e a categoria quatro, possuem outros nove artigos que descreveram as medidas de prevenção, tratamento e controle da $\mathrm{CO}$ VID-19 no Brasil.

\section{Categoria um: chegada de um navio no Porto de Santos com novos casos suspeitos}

Sistemas de transporte aéreos e marítimos podem implicar de forma significativa na propagação de doenças pelo mundo. Por isso, em 19 de fevereiro de 2020 houve uma investigação de um navio de origem Chinesa que desembarcou no Porto de Santos, com 25 tripulantes, de modo a investigar a possibilidade desses tripulantes estarem contaminados pela COVID-19, já que, dois deles apresentaram manifestações evidentes da COVID-19 11 .

Durante a investigação, percebeu-se que esses dois casos suspeitos não se encaixaram no quadro clínico da COVID-19 por não apresentarem febre e pelo menos um sintoma respiratório. Contudo, o primeiro tripulante apresentava dor de garganta, o que levou a administração de um anti-inflatório. $\mathrm{O}$ mesmo permaneceu 14 dias em isolamento enquanto apresentava o sintoma. Já o segundo tripulante, relatou febre do dia 10 de fevereiro de 2020 ao dia 13 de fevereiro de 2020, negando outros sintomas persistentes. Com isso foi administrado um antitérmico, levando-o a cura. O restante dos tripulantes declarou que nos últimos dois meses até a data da investigação não havia sentido nenhum sintoma relativo à COVID-19, não sendo necessário realizar a coleta de material biológico através de swab e solução salina ${ }^{11}$.

\section{Categoria dois: Intervenções não farmacológicas da COVID-19}

Um estudo ressaltou a importância das intervenções não farmacológicas para diminuir a curva epidêmica, visando à redução de morbidade e mortalidade da população brasileira. Entretanto, até o momento, não existe na literatura nenhuma pesquisa que demonstrou a eficácia significativamente superior de uma determinada imunização para a cura dos pacientes infectados pelo SARS-Cov- $2^{12}$.

Ainda dentro desse contexto, os autores ressaltam que é importante adotar prática de higienização das mãos, isolamento social, quarentena e evitar frequentar locais com aglomeração de pessoas, com o objetivo de diminuir o índice de contaminação e propagação da doença. Essa pesquisa ressaltou também que essas medidas que foram tomadas na pandemia da Influenza estão sendo importantes para o enfretamento da COVID-19, uma vez que observaram certa similaridade entre as formas de reação do SARS-Cov-2 e do vírus da Influenza ${ }^{12}$.

A Organização Mundial de Saúde (OMS) até o momento não recomenda o uso de máscaras para os casos assintomáticos, visto que não há comprovações perante a redução de transmissão da Influenza. Sendo assim, não há evidências da efetividade do uso de máscaras para esses casos assintomáticos a fim de prevenir contra a infecção da COVID-19 12 .

Categoria três: medidas da Vigilância em Saúde e os aspectos Epidemiológicos da COVID-19 no Brasil 


\section{artigo}

Ferreira, S.S.R.; Oliveira, J.V.; Souza, D.A.; Carvalho Silva, I.N.; Santos, R.C.; Andrade, S.N.; Carvalho, N.M.

Condutas no Brasil diante da pandemia de COVID-19: revisão integrativa

As condutas determinadas pela Organização Mundial de Saúde (OMS), Secretária de Vigilância em Saúde do Ministério da Saúde (SVS/MS), Governo Federal, Grupo Executivo Interministerial de Emergência em Saúde Pública de Importância Nacional e Internacional (GEI-ESPII), Vigilância em Saúde, Comitê de Emergência, Comitê de Monitoramento de Eventos e o Centro de Operações de Emergência (COE) do Ministério da Saúde para os sistemas de saúde frente à SARS-Cov-2 no Brasil, estão relacionadas à mobilização de especialistas da área de saúde, à instalação de estruturas de laboratórios que ofereçam resultados rápidos e ao uso adequado de equipamentos de proteção individual para os profissionais ${ }^{1,13,14,4}$.

$\mathrm{O}$ uso de plataformas, ferramentas e aplicativos criados e/ou apoiados, pelas autoridades brasileiras podem ampliar as informações com embasamento científico para a população. Mediante a isso, é divulgado na plataforma (http://plataforma.saude.gov.br/novocoronavirus/) o número de casos suspeitos, confirmados e descartados, com o objetivo de tornar as notificações dos casos mais rápidas ${ }^{1,13,4,15}$.

O acompanhamento da curva epidêmica foi uma das ações mais importantes executadas pela Vigilância Epidemiológica. É de fundamental importância para demonstrar os fatores epidemiológicos da atual pandemia da COVID-19. A exposição dos picos poderá contribuir para futuras decisões, de forma a distinguir o melhor momento para a tomada de medidas ${ }^{7,14,4}$.

Outra autoridade brasileira (ANVISAAgência Nacional de Vigilância Sanitária) enfatiza a necessidade de que os testes utilizados para diagnosticar a COVID-19 entre os brasileiros sejam registrados, para que tenham uma exatidão consistente. Uma metánalise que avaliou a precisão desses testes em uso clínico obteve resultados satisfatórios ${ }^{16}$.

Observaram as hospitalizações de síndromes respiratórias agudas graves (SRAG) em períodos anteriores ao início da COVID-19 no Brasil, e verificou-se que se o padrão de internações apresentou alguma modificação. Percebeu-se um acréscimo considerável no número de hospitalizações por SRAG em 2020, relacionado ao novo coronavírus. Quanto à testagem para a detecção do SARS-Cov-2, foram inclusos testes no protocolo da vigilância de SRAG a partir da $12^{a}$ semana epidemiológica, visando à confirmação da hipótese de que a COVID-19 é a principal causa relacionada ao aumento das hospitalizações pela síndrome respiratória aguda grave ${ }^{17}$.

\section{Categoria quatro: medidas de pre- venção, tratamento e controle da COVID-19 no Brasil}

A fim de reduzir a proliferação do SARS-Cov-2 ao longo da atual pandemia, foram realizadas algumas medidas, como, o uso de equipamentos de proteção individual (EPI), manter o espaço arejado, higienizar corretamente as mãos, tampar o nariz e boca com a parte interna do cotovelo ao tossir ou espirrar, evitar locais com aglomeração de pessoas, manter em isolamento por 14 dias os indivíduos com sintomas persistentes a COVID-19, distanciamento social, constatação rápida de casos, adotar quarentena para pessoas notificadas ao novo coronavírus, entre outros $18,19,3,6,9,20,5,2$

Para aqueles pacientes que necessitassem de atendimentos eletivos, seria adequado o reagendamento das consultas, de modo a haver um intervalo de tempo maior entre um paciente e outro. Foram recomendadas também novas rotinas para $o$ atendimento presencial. Este, deveria ter um distanciamento seguro entre o médico e o paciente. A troca de luvas pelo profissional da saúde durante cada atendimento também foi reforçada. Além disso, os estabelecimentos que produzem alimentos $\mathrm{e}$ que servem pessoas saudáveis tiveram suas tarefas bloqueadas $18,19,3,6,9,20,5,2$.

No que se refere aos casos assintomáticos, é de extrema importância o uso de EPI entre os profissionais responsáveis por esses pacientes, para que não haja possíveis contaminações, o que não implica que a mesma conduta seja feita para os casos sintomáticos Em relação ao tratamento dos pacientes com COVID-19, o que se sugere é respeitar as características clínicas de cada paciente para escolher o tratamento mais adequado e individualizado ${ }^{18,2}$.

Para conter a disseminação do vírus, é necessário realizar investimentos em pesquisas, com o objetivo de apresentar dados epidemiológicos quanto aos acontecimentos atuais, além de criar testes, vacinas e medicamentos que previnam e tratem a doença ${ }^{21}$. A administração de fármacos específicos e a imunização da população seriam de grande importância para tratar e prevenir a doença. Porém, até os dias atuais, ainda não há nenhum estudo sobre vacinação e formas de tratamento que sejam eficazes e comprovados cientificamente para conter a COVID-19 no Brasil.

\section{DISCUSSÃO}

Os resultados demonstram a importância das ações de prevenção frente à COVID-19 para a diminuição do número

Tabela 2: Relação dos artigos estudados, adaptado de Souza TS, et al. 22 conforme modificações, título do artigo, autores, periódico e considerações temáticas.
Base de Dados
Título do artigo
Autor
Periódico (vol., $n^{\circ}$, p. ,
2020)
Considerações temáticas
An update on COVID-19 for the otorhinolaryngologist - a Brazilian
BVS via Medline Association of Otolaryngology and Cervicofacial Surgery (ABORL-CCF) Position Statement.
LAVINSKY Brazilian Journal of J., et al. Otorhinolaryngology, v.71, $n^{\circ} 1,2005$.
Apresentam recomendações frente às evidências de COVID-19 para o Otorrinolaringologista.




\begin{tabular}{|c|c|c|c|c|}
\hline & $\begin{array}{l}\text { The surgeons and the COVID-19 } \\
\text { pandemic. }\end{array}$ & $\begin{array}{l}\text { CORREIA, } \\
\text { M.I. T. D.; } \\
\text { RAMOS, R. } \\
\text { F.; BAHTEN, } \\
\text { L. C. V. }\end{array}$ & $\begin{array}{l}\text { Revista do Colégio Brasi- } \\
\text { leiro de Cirurgiões, v.36, } \\
n^{\circ} 1,2009 .\end{array}$ & $\begin{array}{l}\text { Discorre sobre a veracidade de tra- } \\
\text { balhos científicos sobre a COVID-19, } \\
\text { além de medidas tomadas por cirur- } \\
\text { giões frente à pandeia. }\end{array}$ \\
\hline \multirow{8}{*}{ BVS via Medline } & $\begin{array}{l}\text { Food (in) security in Brazil in } \\
\text { the context of the SARS-Cov-2 } \\
\text { pandemic. }\end{array}$ & $\begin{array}{l}\text { OLIVEI- } \\
\text { RA, T. C.; } \\
\text { ABRAN- } \\
\text { CHES, M. } \\
\text { V.; LANA, } \\
\text { R. M. }\end{array}$ & $\begin{array}{l}\text { Cadernos de Saúde Públi- } \\
\text { ca, v.32, n¹, } 2016 .\end{array}$ & $\begin{array}{l}\text { Demonstram medidas tomadas fren- } \\
\text { te à COVID-19 no Brasil de acordo } \\
\text { com a necessidade de se obter uma } \\
\text { segurança alimentar independente } \\
\text { da classe socioeconômica. }\end{array}$ \\
\hline & $\begin{array}{l}\text { How Brazil can hold back CO- } \\
\text { VID-19. }\end{array}$ & $\begin{array}{l}\text { OLIVEIRA, } \\
\text { W. K., et al. }\end{array}$ & $\begin{array}{l}\text { Epidemiologia e Serviços } \\
\text { de Saúde, v.25, n¹, } \\
2016 .\end{array}$ & $\begin{array}{l}\text { Apresentam estratégias e ações } \\
\text { adotadas pelo Ministério da Saúde do } \\
\text { Brasil para deter a COVID-19. }\end{array}$ \\
\hline & $\begin{array}{l}\text { How should health systems } \\
\text { prepare for the evolving COVID-19 } \\
\text { pandemic? Reflections from the } \\
\text { perspective of a Tertiary Cancer } \\
\text { Center. }\end{array}$ & $\begin{array}{l}\text { CHEN, A. T. } \\
\text { C., et al. }\end{array}$ & Clinics, v.60 , nº1, 2005 & $\begin{array}{l}\text { Sob perspectiva de um Centro } \\
\text { Terciário de Câncer do Estado de São } \\
\text { Paulo, discute condutas que foram } \\
\text { realizadas em outras condições de } \\
\text { emergência e durante a pandemia da } \\
\text { COVID-19 no Brasil. }\end{array}$ \\
\hline & $\begin{array}{l}\text { Management of inflammatory } \\
\text { bowel disease patients in the CO- } \\
\text { VID-19 pandemic era: a Brazilian } \\
\text { tertiary referral center guidance. }\end{array}$ & $\begin{array}{l}\text { QUEIROZ, } \\
\text { N. S. F., et } \\
\quad \text { al. }\end{array}$ & Clinics, v. , no , p. , 2020. & $\begin{array}{c}\text { Relatam sobre o tratamento de } \\
\text { pacientes com doença inflamatória } \\
\text { intestinal (DII) durante o tempo da } \\
\text { pandemia de COVID-19 que apoiam } \\
\text { a reconstituição da unidade de DII e } \\
\text { os conselhos clínicos fornecidos aos } \\
\text { pacientes. }\end{array}$ \\
\hline & $\begin{array}{l}\text { What is urgent and necessary to } \\
\text { inform policies to deal with the } \\
\text { COVID-19 pandemic in Brazil? }\end{array}$ & $\begin{array}{l}\text { BARRETO, } \\
\text { M. L., et al. }\end{array}$ & $\begin{array}{l}\text { Revista Brasileira de } \\
\text { Epidemiologia, v. , nº, p. } \\
\text {,2020. }\end{array}$ & $\begin{array}{l}\text { Retrata a urgência e importância de } \\
\text { dados confiáveis e de qualidade fren- } \\
\text { te à pandemia de COVID-19 no Brasil, } \\
\text { além de evidenciar o desenvolvimen- } \\
\text { to de uma série de ferramentas e } \\
\text { plataformas para oferecer as melho- } \\
\text { res referências sobre o impacto atual } \\
\text { e futuro da pandemia no país. }\end{array}$ \\
\hline & $\begin{array}{l}\text { Intervenções não farmacológicas } \\
\text { para o enfrentamento à epidemia } \\
\text { da COVID-19 no Brasil. }\end{array}$ & $\begin{array}{l}\text { GARCIA, L. } \\
\text { P.; DUARTE, } \\
\text { E.. }\end{array}$ & $\begin{array}{c}\text { Epidemiologia e Serviços } \\
\text { de Saúde, v. } 12, n^{\circ} 3 \\
2003 .\end{array}$ & $\begin{array}{l}\text { É listadas medidas não farmacológi- } \\
\text { cas individuais, ambientais e comu- } \\
\text { nitárias que são de total importância } \\
\text { no enfretamento da COVID-19 no } \\
\text { Brasil na ausência de vacinas. }\end{array}$ \\
\hline & $\begin{array}{c}\text { COVID-19 and hospitalizations for } \\
\text { SARI in Brazil: a comparison up to } \\
\text { the 12th epidemiological week of } \\
2020 \text {. }\end{array}$ & $\begin{array}{l}\text { BASTOS, L. } \\
\text { S., et al. }\end{array}$ & $\begin{array}{l}\text { Cadernos de Saúde Públi- } \\
\text { ca, v. } 14, n^{\circ} 1,1998 .\end{array}$ & $\begin{array}{c}\text { Comparação das hospitalizações de } \\
\text { casos de SRAG (Síndrome Respira- } \\
\text { tória Aguda Grave) e COVID-19 entre } \\
\text { períodos diferentes. }\end{array}$ \\
\hline & $\begin{array}{l}\text { Resposta imediata da Vigilância } \\
\text { em Saúde à epidemia da CO- } \\
\text { VID-19. }\end{array}$ & $\begin{array}{l}\text { CRODA, J. } \\
\text { H. R.; GAR- } \\
\text { CIA, L. P. }\end{array}$ & $\begin{array}{c}\text { Epidemiologia e Serviços } \\
\text { de Saúde, v. 25, n 1, } \\
2016 .\end{array}$ & $\begin{array}{c}\text { Descrevem medidas que foram } \\
\text { tomadas a partir da constatação } \\
\text { de rumores do SARS-Cov-2, além } \\
\text { do aumento de casos suspeitos, } \\
\text { confirmados e descartados na China } \\
\text { e no Brasil, conforme a Vigilância em } \\
\text { Saúde. }\end{array}$ \\
\hline
\end{tabular}




\section{artigo}

Ferreira, S.S.R.; Oliveira, J.V.; Souza, D.A.; Carvalho Silva, I.N.; Santos, R.C.; Andrade, S.N.; Carvalho, N.M.

Condutas no Brasil diante da pandemia de COVID-19: revisão integrativa

\begin{tabular}{|c|c|c|c|c|}
\hline BVS via Medline & $\begin{array}{l}\text { Emergência do novo coronavírus } \\
\text { (SARS-CoV-2) e o papel de uma } \\
\text { vigilância nacional em saúde opor- } \\
\text { tuna e efetiva. }\end{array}$ & $\begin{array}{l}\text { LANA, R. } \\
\text { M., et al. }\end{array}$ & $\begin{array}{l}\text { Cadernos de Saúde Públi- } \\
\text { ca, v. 14, n 1, } 1998 .\end{array}$ & $\begin{array}{l}\text { Compara a velocidade de reprodu- } \\
\text { ção, de letalidade e de avanços na } \\
\text { vigilância epidemiológica entre a } \\
\text { cOVID-19 e outras doenças no Brasil } \\
\text { durante períodos de epidemia, além } \\
\text { de apresentar situações que são um } \\
\text { desafio para uma melhor eficácia no } \\
\text { combate à doença. }\end{array}$ \\
\hline \multirow[t]{4}{*}{ Lilacs } & $\begin{array}{c}\text { Epidemiologia, políticas públicas e } \\
\text { pandemia de COVID-19 no Brasil: } \\
\text { o que esperar no Brasil? }\end{array}$ & $\begin{array}{l}\text { RAFAEL, R. } \\
\text { M. R., et al. }\end{array}$ & $\begin{array}{c}\text { Revista Enfermagem Uerj } \\
\text { (Universidade do Estado } \\
\text { do Rio de Janeiro), v. , } \mathrm{n}^{\circ} \text {, } \\
\text { p., } 2020 .\end{array}$ & $\begin{array}{l}\text { Argumentam experiências e dife- } \\
\text { renças no controle da pandemia da } \\
\text { COVID-19 perante o ponto de vista } \\
\text { da epidemiologia e das políticas } \\
\text { públicas brasileiras. }\end{array}$ \\
\hline & $\begin{array}{l}\text { Outbreak investigation in cargo } \\
\text { ship in times of COVID-19 crisis, } \\
\text { Port of Santos, Brazil. }\end{array}$ & $\begin{array}{l}\text { FERNAN- } \\
\text { DES, E. G., } \\
\text { et al. }\end{array}$ & $\begin{array}{l}\text { Revista de Saúde Pública, } \\
\text { v. } 48, n^{\circ}, 2014 .\end{array}$ & $\begin{array}{l}\text { Averigua a possibilidade de haver } \\
\text { casos confirmados pela COVID-19 } \\
\text { entre os tripulantes de um navio que } \\
\text { desembarcou no Porto de Santos, em } \\
\text { cumprimento ao plano de contin- } \\
\text { gência para infecção humana com o } \\
\text { SARS-Cov-2 no estado de São Paulo. }\end{array}$ \\
\hline & $\begin{array}{l}\text { COVID-19 and dengue fever: A } \\
\text { dangerous combination for the } \\
\text { health system in Brazil. }\end{array}$ & $\begin{array}{l}\text { LORENZ, C.; } \\
\text { AZENVE- } \\
\text { DO, T. S.; } \\
\text { NETO, F. C. }\end{array}$ & $\begin{array}{l}\text { The Journal of Minimally } \\
\text { Invasive Gynecology, v. 1, } \\
n^{0} 1,2003 .\end{array}$ & $\begin{array}{c}\text { Retratam medidas preventivas, quais } \\
\text { são e sua importância na ausência } \\
\text { de vacinas, além de demonstrar a } \\
\text { similaridade da COVID-19 e Dengue } \\
\text { frente às características clinicas e } \\
\text { laboratoriais. }\end{array}$ \\
\hline & $\begin{array}{l}\text { COVID-19: a meta-analysis of } \\
\text { diagnostic test accuracy of com- } \\
\text { mercial assays registered in Brazil. }\end{array}$ & $\begin{array}{l}\text { CASTRO, R., } \\
\text { et al. }\end{array}$ & $\begin{array}{l}\text { The Brazilian Journal of } \\
\text { INFECTIOUS DISEASES, v. } \\
\text {, } \mathrm{n}^{\circ}, \mathrm{p} \text {. , ano. }\end{array}$ & $\begin{array}{c}\text { Discorre sobre a precisão de testes } \\
\text { disponiveis para detecção de CO- } \\
\text { VID-19 no Brasil. }\end{array}$ \\
\hline \multirow[t]{3}{*}{ PubMed } & $\begin{array}{l}\text { COVID-19 in Brazil: advantages of } \\
\text { a socialized unified health system } \\
\text { and preparation to contain cases. }\end{array}$ & $\begin{array}{l}\text { CRODA, J., } \\
\text { et al. }\end{array}$ & $\begin{array}{l}\text { Revista da Sociedade } \\
\text { Brasileira de Medicina } \\
\text { Tropical, v. 28, n , } 1995 .\end{array}$ & $\begin{array}{l}\text { Detalha a experiência do Brasil em } \\
\text { outras emergências de saúde, em } \\
\text { erros cometidos durante a tentativa } \\
\text { de combate ao vírus e em ações } \\
\text { tomatadas para o enfrentamento da } \\
\text { doença. }\end{array}$ \\
\hline & $\begin{array}{l}\text { How Brazil Is Dealing with } \\
\text { COVID-19 Pandemic Arrival } \\
\text { Regarding Elective Gynecological } \\
\text { Surgeries. }\end{array}$ & $\begin{array}{l}\text { BRITO, L. G. } \\
\text { O., et al. }\end{array}$ & $\begin{array}{l}\text { The Journal of Minimally } \\
\text { Invasive Gynecology, v. , } \\
n^{\circ}, p_{\text {. }}, 2020 \text {. }\end{array}$ & $\begin{array}{c}\text { Retratam que a sociedade obstétrica } \\
\text { e ginecológica (Federação Brasilei- } \\
\text { ra de Associações de Ginecologia } \\
\text { e Obstetrícia) e várias sociedades } \\
\text { afiliadas, por exemplo, Associação } \\
\text { Brasileira Uroginecologia e Pélvico e } \\
\text { Endometriose e Sociedade Minima- } \\
\text { mente Invasiva estão se preparan- } \\
\text { do para orientar os membros das } \\
\text { Associações quanto às precauções } \\
\text { e medidas de cirurgias ginecológicas } \\
\text { eletivas. }\end{array}$ \\
\hline & $\begin{array}{l}\text { COVID-19 in Brazil: Historical } \\
\text { cases, disease milestones, and } \\
\text { estimated outbreak peak. }\end{array}$ & $\begin{array}{l}\text { SERDAN, T. } \\
\text { D. A., et al. }\end{array}$ & $\begin{array}{c}\text { Travel Medicine and } \\
\text { Infectious Disease, v. 1, } \\
n^{\circ} 1,2003 .\end{array}$ & $\begin{array}{c}\text { Destaca a influência das decisões } \\
\text { e medidas tomadas pelo governo } \\
\text { de São Paulo no aumento de casos } \\
\text { confirmados, dando ênfase no pico } \\
\text { da epidemia em um dos estados bra- } \\
\text { sileiros que é considerado o Epicentro } \\
\text { do país. }\end{array}$ \\
\hline
\end{tabular}




\section{PubMed}

COVID-19 in Latin America: The implications of the first confirmed case in Brazil.
MORALES,

A. J. R., et al.
Travel Medicine and

Infectious Disease, v. $1, n^{\circ}$ 1, 2003.
Relata o início de rastreamento e investigação de contatos e casos suspeitos além de demonstrar uma preocupação com a possivel falta de preparo dos sistemas de saúde e de equipamentos suficientes para os pacientes.

Fonte: Dados da pesquisa, 2020. w

de casos confirmados da doença. Enfatizaram também a necessidade da realização de testes rápidos, para discriminar os casos suspeitos dos confirmados e rastrear os comunicantes, a fim de colocá-los em quarentena, de modo a evitar a contaminação de mais pessoas. Além disso, realçam a importância do isolamento social para o controle do número de casos, visto que, indivíduos assintomáticos também contribuem para a transmissão da doença. Apontam ainda, que é indispensável à utilização de EPI, visando à proteção dos profissionais da saúde.

Diante de uma epidemia, o acompanhamento do número de casos pelos serviços de vigilância é realizado para predizer o cenário epidemiológico, e desta forma delinear as melhores políticas públicas para o enfrentamento desta eventualidade. Tratando-se de um novo vírus, a suscetibilidade da população em ser infectada é bem maior, o que implica na acentuação da velocidade da ocorrência dos picos epidêmicos, situação, a qual o sistema de saúde brasileiro não está suficientemente preparado para enfrentar. Perante isso, a vacinação seria a medida ideal para imunizar a população e consequentemente promover o achatamento da curva epidêmica, porém, como atualmente não é uma realidade, intervenções de restrição de contato ajudaram a prorrogar o tempo de ocorrência dos casos. ${ }^{7}$

Após a implementação do isolamento social no país e em especial pelo governo do Rio de Janeiro, houve uma expressiva redução da reprodução da doença, antes, estimada entre 2,4 a 4,6 pessoas, caindo para 2,1 e 3,8 pessoas, isto em um dia. O tempo de duplicação da epidemia também apresentou uma pequena melhora quando comparados aos dois períodos: entre 2,0 e
2,9 dias e 2,9 e 3,3 dias, respectivamente ${ }^{7}$. A pandemia causada pelo SARS-Cov-2 gerou e tem gerado transtorno para a população brasileira, devido a circulação de informações incoerentes e acessos em sites não confiáveis ${ }^{4}$. Devido a isso, o Ministério da Saúde (MS) tem tomado medidas fundamentais para restringir publicações falsas. Para isso, eles forneceram novos meios de informações para ajudar a população, como por exemplo: a criação do aplicativo Coronavírus SUS e um canal específico do WhatsApp. Além disso, foram criadas plataformas e ferramentas nos últimos meses para divulgações de informações confiáveis sobre as consequências atuais e futuras causadas pela COVID-19. As plataformas podem ser acessadas através dos seguintes links: http://covid19br. org/main-site-covida/; https://bigdata-covid19.icict.fiocruz.br; https://sites. google.com/view/nois-pucrio:https:// COVID-19.procc.fiocruz.br/; https:// ciis.fmrp.usp.br/covid19/ ${ }^{15}$.

Lana et al. ${ }^{13}$ também destacam em seu estudo, a criação da Plataforma Integrada de Vigilância em Saúde (Plataforma IVIS) http://plataforma.saude.gov.br/ novocoronavirus/, que busca objetivar a visualização de informações (casos confirmados, óbitos, prevenções, recomendações, etc.) da COVID-19. A criação desses aplicativos e plataformas é relevante, já que fornece para a sociedade, informações com embasamento científico, transmitindo confiança e conhecimentos. Barreto et al. ${ }^{15}$, cita que no Brasil existe uma grande dificuldade quanto as escolhas de melhores procedimentos a serem empregados para o combate da pandemia. O Colégio Brasileiro de Cirurgiões concorda que apesar de haver inúmeras informações, as evidências científicas são débeis, e com isso sugerem iniciativas qualificadas para auxiliar os pacientes e profissionais de saúde frente à pandemia de SARS-Cov- ${ }^{19}$.

Oliveira, Duarte, França, e Garcia ${ }^{4}$, evidenciaram que à alta transmissibilidade do vírus por casos assintomáticos, possibilita o aumento na incidência $\mathrm{da}$ infecção e consequentemente no aumento do número de casos graves que possam superar a capacidade dos serviços de saúde. Mizumoto, Kagaya, Xarebski, e Chowell ${ }^{23}$ acreditam que pessoas assintomáticas podem possuir uma participação significativa na disseminação do vírus, sustentar a transmissibilidade, bem como, dificultar o controle da pandemia. Um estudo com tripulantes e passageiros de um navio que se atracou em Yokohama (Japão) verificou que, após um ex passageiro desembarcar em Hong Kong e testar positivo para coronavírus, mesmo assintomático, outros passageiros que tiveram contato com ele, também testaram positivo. Dos 3711 passageiros do navio, 634 testaram positivo para o SARS-Cov-2, sendo que 328 , não manifestaram a doença, o que corresponde a mais das metades das pessoas infectadas no navio.

Devido à alta transmissibilidade da COVID-19, as autoridades de saúde brasileiras agiram com rapidez frente à emergência eminente da pandemia. Antes mesmo dos primeiros casos surgirem no Brasil, algumas ações foram tomadas. Em 10 de janeiro foi declarado Emergência Nacional de Saúde Pública (NPHE). Em 22 de janeiro o Ministério da Saúde ativou o Centro de Operações de Emergência em Saúde (EHOC-nCoV) pelo decreto n.188 11, com nível de alerta 1.

O objetivo do EHOC-nCov coordenado pela Secretaria de Vigilância Sanitária (HSS) é aconselhar os secretários estadu- 
ais e municipais de saúde, o governo federal, os serviços públicos e privados de saúde, as agências e empresas, sobre os planos de contingência e estratégias de resposta de acordo com o risco de cada região. Em 26 de janeiro, foi constatado o primeiro caso suspeito de coronavírus no Brasil, o que levou ao aumento do nível de alerta para o nível 2 (risco iminente). Destacam-se ainda as ações frente ao primeiro caso no país como: identificação, rastreamento de contatos em casa, no hospital e no voo em que o paciente infectado percorreu ${ }^{5}$.

Com intuito de prevenir e controlar o coronavíruis no Brasil, ainda foram criadas medidas como, a Plataforma Integrada de Vigilância em Saúde (Plataforma IVIS), implementação dos Planos de Contingência e aumento dos números de leitos nos hospitais de referências, nas distintas localidades do país1. Além disso, Oliveira, Duarte, França, e Garcia4 apontam também a preocupação das autoridades brasileiras voltadas para produção, aquisição e distribuição EPI a todos profissionais da saúde. Houve a ampliação das estruturas para atendimento, criação do programa "Brasil Conta Comigo" que visa a capacitação dos profissionais de saúde, apoio ao aumento da produção e aquisição de ventiladores mecânicos, expansão do número de testes para diagnosticar a doença e disponibilização de cerca de 1 bilhão de reais aos Estados e municípios para financiar ações contra o COVID-19.

Croda, Garcial, destaca em seu estudo a importância do uso de EPI para os profissionais de saúde, visto que desprotegidos há uma maior facilidade de disseminação do vírus nos serviços de saúde. A literatura ainda enfatiza que os sistemas de saúde devem reforçar os hospitais campanhas e alocar mais profissionais na busca da prevenção frente a pandemia ${ }^{29,30}$.

Há ainda, outras evidências de condutas brasileiras como: antecipação da campanha de vacinação contra Influenza para pessoas com comorbidades e profissionais de saúde; o estabelecimento de "home work" para trabalhadores públicos; fechamento de bibliotecas, museus, templos religiosos, zoológicos, parques, restaurantes, bar e boates14. Além disso, Croda et al.9 menciona medidas como: uso da cloroquina e hidroxicloroquina em pacientes graves como medida complementar, isolamento social e quarentena.

Wang J, Wang $\mathrm{Z}^{24}$ revela que algumas medidas tomadas pelas autoridades brasileiras, foram semelhantes aquelas desenvolvidas na China como: o desenvolvimento de um sistema de emergência de saúde que possibilita o desempenho na orientação, prevenção e controle no combate à pandemia, fortalecimento dos serviços de saúde, investimentos em pesquisas, adiamento do início do semestre escolar, disponibilização de informações gerais sobre a epidemia e conteúdos enriquecedores para a população através da televisão e do rádio.

Realça, o controle de tráfego, aumento da supervisão dos comércios em principal os de aves e animais selvagens, aplicação de verbas com fins para prevenção e controle do vírus. Também evidencia uma grande discrepância entre a demanda e oferta de materiais (máscaras e roupas de proteção) de prevenção contra o vírus, e que poderia levar a falta deles. Por essa razão, a China aumentou cerca de $40 \%$ a produção de materiais de proteção e atentou-se ao controle dos comércios e usos destes materiais nos estabelecimentos para que a demanda necessária fosse atendida ${ }^{24}$.

Bastos et al. ${ }^{17}$, Lorenz, Azevedo, Neto ${ }^{21}$, e Morales et al. ${ }^{5}$ trazem a preocupação do impacto que a COVID-19 poderia ter no Brasil, por já enfrentar outras doenças infecciosas como a Influenza (H1N1), Dengue, Zika e Chikungunya entre outras. Reforçam que a probabilidade dos surtos acontecerem simultaneamente é evidente, já que no final de abril e início de maio seria o pico máximo da COVID-19, segundo estimativa dos estatísticos e epidemiologistas no Brasil, fato que coincidiria com o aumento dos casos de doenças respiratórias. Isso sobrecarregaria ainda mais os serviços de saúde, que poderiam não ter unidades de terapia intensiva (UTI) para todos os pacientes. Esse contexto justificou o adiantamento da campanha de vacinação contra a $\mathrm{H} 1 \mathrm{~N} 1$, o que também contribuiu para a identificação de possíveis casos entre os profissionais de saúde.

No Brasil, existe atualmente cerca de, 16 testes diagnósticos disponíveis e registrados na Agência Nacional de Saúde Suplemen$\operatorname{tar}$ (ANVISA). Eles são divididos em dois tipos: reação em cadeia da polimerase em tempo real (PCR) e testes rápidos (sorológicos). Entretanto a distribuição e disponibilidade são controladas pelas autoridades. A maior parte dos testes realizados são sorológicos, que têm como foco a detecção de anticorpos IgM (imunoglobulina M) e / ou IgG (imunoglobulina $G)^{16}$.

A precisão diagnóstica dos testes disponíveis no Brasil é satisfatória. Contudo, cabe ressaltar que a taxa de resultados falsos negativos dos testes que detectam anticorpos IgM que caracteriza os anticorpos da fase aguda na infecção, obteve uma variação de 10 à $44 \%$, o que pode ser considerada alta. Por este motivo, o ideal é que os testes sejam realizados após 3-6 dias após o início dos sintomas, de forma a diagnosticar os anticorpos IgM, e após 8 dias para identificar o IgG, o que diminuiria a taxa de falsos negativos ${ }^{16}$.

Um resultado falso negativo impede a determinação de precauções essenciais como, o isolamento deste indivíduo, o que colaboraria para a propagação do vírus. Para haver a redução da pandemia da COVID-19 é necessário a oferta de testes em larga escala, para que se haja um diagnóstico rápido, e consequentemente o isolamento imediato dos casos positivos e de contatos próximos como forma de prevenção 16. Entretanto, mesmo com a ampliação dos testes no Brasil, a demanda de casos que necessitam da testagem para diagnóstico está superando a quantidade de testes disponíveis?.

Perante essa situação, o Ministério da Saúde (MS) orientou a priorização dos testes para pacientes em estados graves internados em terapia intensiva. Os demais casos deveriam ser instruídos a adotar o isolamento domiciliar, sem necessidade de notificação às autoridades sanitárias ${ }^{25}$. No entanto, ao observar essa orientação do MS, é perceptível que haveria uma possível sub-notificação dos casos menos graves da 
doença, e como visto pela experiência dos outros países, a maior parte dos acometidos pela COVID-19 apresentam a doença da forma mais brandaz.

Com o avanço da pandemia causada pelo SARS-CoV-2 no Brasil, variados serviços, instituições e empresas sofreram alterações em suas atividades cotidianas. Algumas condutas, foram implementadas pelas autoridades de saúde eclínicas, supermercados, consultórios entre outros comércios essenciais, para que estes continuassem funcionando durante a pandemia, visto que durante a fase inicial desse surto permaneceram fechados ${ }^{3}$.

Oliveira, Abranches, Lana ${ }^{3}$ abordaram em seu estudo, condutas para estabelecimentos que produzem ou distribuem alimentos. Nesse mesmo estudo, aponta que em 16 de março a Secretaria de Estado de Agricultura, Pecuária, Pesca e Abastecimento do Estado do Rio de Janeiro instituiu, por meio da Portaria PRESI/ CEASA-RJ no 17, o Programa Extraordinário de Prevenção à Contaminação, que dentre as medidas impostas encontra-se: evitar contato pessoal entre os colaboradores (tendo preferência ao uso de tecnologias para a comunicação), realização das refeições na própria estação de trabalho, restrição da presença dos colaboradores a presença na sede e notificação quando houver casos suspeitos. Além disso, medidas como espaçamento de 3 metros entre as mesas e a diminuição da capacidade de lotação dos estabelecimentos para 30\%, foram instituídas no Distrito Federal e Rio de Janeiro, respectivamente.

Serviços como de take out/away, delivery e retirada na loja, estão sendo recomendadas aos comércios, visto que minimiza o risco de aglomeração. A Associação Brasileira de Supermercados estabeleceu uma cartilha divulgando estratégias para minimizar o risco de contágio, na qual destaca; a necessidade de higienização com álcool $70 \%$ de superfícies e objetos onde são frequentes tocados por clientes e colaboradores, carrinhos, cestas de compra, maçanetas, corrimãos, terminais de pagamento, alimentos, embalagens de alimentos, caixas eletrônicos e elevadores.

\section{No Brasil, devido}

à chegada da

COVID-19 foi

necessário o

reagendamento de

vários procedimentos

eletivos. A Associação

Americana de

Laparoscopistas

Ginecológicos,

assim como, várias

sociedades reforçam

a necessidade de

reagendar as cirurgias

eletivas, mas enfatiza

a discussão desta ação

entre o cirurgião e

paciente.

Preconiza também que devem ficar disponíveis ao público suportes com álcool em gel na entrada da loja e de sabonete e papel toalha nos banheiros, além de restrição de número de clientes dentro da loja ${ }^{3}$.

No Brasil, devido à chegada da COVID-19 foi necessário o reagendamento de vários procedimentos eletivos. A Associação Americana de Laparoscopistas Ginecológicos, assim como, várias sociedades reforçam a necessidade de reagendar as cirurgias eletivas, mas enfatiza a discussão desta ação entre o cirurgião e paciente ${ }^{20}$.

Queiroz et al. ${ }^{2}$, Lavinsky et al. ${ }^{18}$, Correia, Ramos, Bahten ${ }^{19}$, Chen et al. ${ }^{6}$ reforçam a mesma adoção sobre o adiamento das cirurgias eletivas. Sugerem que para os pacientes que necessitam de cirurgias de forma imediata, ou não possa ser feito o reagendamento, que os pacientes sejam submetidos a testes diagnóstico para $\mathrm{CO}$ VID-19 antes da realização dos procedimentos, e que além disso, seja feito uso de equipamentos de proteção individual por toda equipe, bem como número restrito de pessoas dentro da sala cirúrgica.

Correia, Ramos, Bahten ${ }^{19}$ mencionam outras medidas para cirurgióes, como: definir salas específicas para a realização de operações; cuidado rigoroso com o uso aparelhos de aspiração e cauterização; insuflação em operações laparoscópicas ou abertas devido a produção de aerossóis; utilização do cautério com a menor potência ; desinfecção da sala e de todos materiais usados de acordo com as recomendações das autoridades sanitárias e limitação do número de visitas, principalmente a pacientes em UTI.

Ainda em se tratando de atendimento, o TeleSUS é uma forma de rastreamento artificial de casos suspeitos da COVID-19 por chamadas telefônicas. A Telemedicina têm sido uma grande aliada para pacientes e médicos (as), visto que é de fundamental importância para assistência as pessoas que necessitam de atendimento médico, sejam elas afetadas pela COVID-19 ou não. Este método de atendimento se torna interessante neste período porque não há necessidade de contato presencial com os pacientes, o que diminui dessa forma, a possibilidade de qualquer transmissão. $\mathrm{O}$ Conselho Federal de Medicina contribuiu para que a Telemedicina fosse organizada, e produziu alguns regulamentos para as consultas médicas online, sendo o telesurgery e telediagnosis, entre outras ${ }^{4}$.

Lavinsky et al. ${ }^{18}$, relatam que a partir do dia 19 de março de 2020 houve a divulgação de uma nota da Associação Brasileira de Medicina recomendando a suspensão de atendimentos ambulatoriais para otorrinolaringologista, sendo fortalecido pelo 
Conselho Federal de Medicina. Mediante a essa implementação, as consultas médicas seriam de grande parte online.

Para aqueles pacientes que necessitam de atendimento ambulatorial, devem ser tomadas medidas como: os pacientes sintomáticos devem ser instruídos a utilizarem máscaras cirúrgicas e aguardarem em uma sala individual, manter sempre os ambientes (recepção e consultório) bem arejados, uso de máscara por todos funcionários. Durante a consulta, independente do procedimento, o uso de EPI tanto para o paciente quanto para o profissional é indispensável ${ }^{26}$.

Atualmente, é recomendado que todas as pessoas utilizem máscaras caso necessitem sair de casa, devido as pesquisas apontarem que o uso de máscaras de tecido é efetivo, já que garantem uma barreira física para as gotículas produzidas pelo indivíduo para o ambiente. Em casos de pessoas assintomáticas em isolamento domiciliar, devem utilizar máscara em suas residências, visto que há um grande risco de contaminação pelos outros habitantes na mesma casa ${ }^{26}$.

As medidas não farmacológicas contribuíram para a não propagação do vírus entre a população'. Garcia, Duarte ${ }^{12}$ mostram que as intervenções não farmacológicas (INF), têm a finalidade de tentar diminuir a curva e o nível epidêmico quanto ao surto de COVID-19 no Brasil, além de restringir a transmissão de pessoa para pessoa e diminuição da mortalidade. Essas medidas são de alcance ambiental (limpeza do ambiente, objetos, maçanetas, veículos, etc.), individual (máscara, luva, higienização das mãos, etiqueta respiratória e distanciamento social) e comunitário (ações realizadas que visam à restrição de escolas, universidades, transporte público e local com aglomeração de pessoas, entre outros).

As INF atualmente podem ser a melhor estratégia para mitigação do vírus até que se desenvolva uma vacina contra a doença, entretanto a paralisação de todas as atividades não essenciais deve ser avaliada com cuidado pois, afetaria a economia do País. Entretanto se não adotadas implicaria no aumento da disseminação da doença

\section{A implantação dos planos de contingências}

é importante

para prevenção

da dispersão do

COVID-19, visto

que o palo apresenta

as principais ações

que devem ser

tomadas pelas

organizações e

população.

o que causaria um dano bem maior ${ }^{12}$. Por isso Garcia, Duarte ${ }^{12}$ e Cimermam, Chebado, Cunha, Morales ${ }^{27}$ concordam que está decisão deve ser avaliada com cautela, pois quanto mais cedo for implementada esta ação, menor será a difusão da doença.

Garcia, Duarte ${ }^{12}$, ainda destacam a dificuldade para a implementação dessas INF para pessoas com vulnerabilidades, como moradores de ruas, idosos institucionalizados e entre outros, já que estes grupos teriam grande dificuldade para seguir essas intervenções, já que, muitas vezes, nos ambientes em que eles vivem, não há ventilação adequada, água canaliza, espaço sufiente, entre outros.

Perante o surto de pneumonia de origem desconhecida na Província de Hubei (Wuhan-China), Pan et al. ${ }^{28}$, levanta que mais de 40 mil pessoas foram infectadas em apenas um mês, preocupando as autoridades de saúde, o governo e a população. Contudo, vinte e cinco dias após essa situação, Hubei estabeleceu as mais rigorosas restrições de tráfego na área onde a doença teve origem, na tentativa de inibir a propagação do vírus. Observou-se que essa medida estabelecida pela Província de Hubei frente à epidemia, fez com que ocorresse uma diminuição em 10 dias na taxa de aparecimento de novos casos na Província de Hubei quando comparadas as outras localidades da China o que indica precocemente a efetividade desta ação.

Cabe salientar, algumas açôes definidas pelo governo Chinês, como: isolamento social, construção de inúmeros hospitais, convocação de mais 10.000 médicos para atuar na Província de Hubei, disponibilização de informações diariamente sobre a epidemia para a população, auxílio financeiro aos empresários e funcionários e investimento em pesquisa. Essas ações foram essenciais, pois caso contrário, a taxa de transmissão seria ainda mais elevada e ocorreria em um curto espaço de tempo e o número de casos confirmados para a COVID-19 seria superior ao observado atualmente bem como o número de mortes ${ }^{28}$.

A implantação dos planos de contingências é importante para prevenção da dispersão do COVID-19, visto que o palo apresenta as principais ações que devem ser tomadas pelas organizações e população ${ }^{11}$. Medidas como essas fazem total diferença no curso de uma epidemia, inclusive impede que ela se torne uma pandemia.

Fernandes, Santos, Sato ${ }^{11}$ evidenciaram algumas condutas de segurança tomadas em um navio de carga no Porto de Santos (BRASIL), seguindo as recomendações do plano de contingência. Foram realizadas entrevistas guiadas por questionário semiestruturado, isolamento social dos 
tripulantes até a averiguação dos casos, utilização de EPI pelos profissionais, preparação para situação de emergência (ambulância de plantão preparada para locomoção dos tripulantes caso fosse necessário), averiguação e notificação.

A pouca ventilação existente dentro dos espaços das embarcações, facilita a transmissão do vírus de pessoa a pessoa, além da introdução do vírus em diferentes áreas após o desembarque dos passageiros ${ }^{11}$. Cabe realçar, que os planos de contingências são documentos produzidos a partir de evidências acumuladas de outros países, em especial a China, além de serem baseados em informações da OMS e evidências científicas, o que auxilia muito o Brasil a lidar com a pandemia da COVID-199.

Ainda estamos vivenciando a pandemia de COVID-19 no Brasil, assim como outros países. Mas de acordo com a trajetória de outros países, acredita-se que as medidas preventivas adotados no Brasil trarão diversos benefícios. No dia 28/4 foram registrados 5.017 óbitos pelo coronavírus no Brasil, o que ultrapassou o número de casos fatais na China, que segundo a OMS, registrou nesta mesma data 4.643 mortes. O número de casos devido a COVID-19 no Brasil continua expandindo, e atualmente foram contabilizados 411.821 casos confirmados, 25.598 óbitos, letalidade de 6,2\%. A maior parte das notificações está centralizada em São Paulo, com 89,483 casos e 6,712 mortes, e posteriormente, Rio de Janeiro com 42.398 casos e 4,605 óbitos. O MS afirma que cada região deve ser tratada de forma distinta conforme as necessidades locais relata estar reforçando a aquisição de respiradores, EPI e profissionais para atuação na linha de frente ${ }^{31}$.

De acordo com Hung et al..$^{32}$, é de extrema importância a utilização de antivirais altamente ativos específicos para tratar esta nova doença infecciosa causada pelo vírus SARS- COV-2. Entretanto, o desenvolvimento de um novo antiviral poderia levar anos até sua aprovação para uso clínico. Contudo, o redirecionamento de medicamentos antivirais existentes de amplo espectro que já foram usados para tratar outras doenças virais, pode ser uma abordagem considerada, conduta a qual está sendo pensada por vários centros de pesquisas atualmente.

No Brasil, o MS implementou em 27 de março o uso da cloroquina e hidroxicloroquina em pacientes graves como medida complementar, visto que em vários estudos o uso dessa medicação demonstrou resultados positivos, por promover a diminuição da carga viral em pacientes ${ }^{9}$. Já o estudo de Hung et al. ${ }^{32}$, demostrou que o tratamento precoce com a tripla combinação de, interferon beta-1b, lopinavir - ritonavir e ribavirina é seguro e muito efetivo. Além disso, o tratamento com essa terapia antiviral tripla, tornou negativa a carga viral nas amostras em até 8 dias após o início do tratamento.

Apesar de haver alguns eventos adversos gastrointestinais e autolimitantes de diarreia e vômito, o tratamento com interferon beta- $1 \mathrm{~b}$, lopinavir - ritonavir e ribavirina demonstrou ser bem eficaz. A única limitação é que as enzimas hepáticas podem aumentar durante o uso dos medicamentos, retornando ao normal após a interrupção do uso. Ainda cabe ressaltar, que fazendo uso desta tripla combinação, os pacientes permaneciam pouco tempo no ambiente hospitalar, o que seria uma solução para os sistemas de saúde, uma vez que muitos deles estão preparados para um pico epidêmico ${ }^{32}$.

Quarentena, distanciamento social e redução de aglomerações, foram efetivados durante a pandemia de influenza em 1918 e 1919, em algumas cidades dos Estados Unidos ${ }^{1}$. No dia 3 de fevereiro de 2020, com a Declaração de Emergência em Saúde Pública de Importância Nacional (ESPIN), o MS aprovou a lei $n^{\circ}$ 13.97916 que leva o nome: (Lei de Quarentena), e que estabelece condutas destinadas a proteção da comunidade e auxiliar Serviço Nacional de Saúde (PHE) no enfrentamento da COVID-19, adotando: o isolamento, quarentena, notificação obrigatória, estudo epidemiológico ou investigação, exumação, necrópsia, cremação e manejo de cadáveres, restrição excepcional e temporária à entrada e saída do país; requerimento de bens e serviços de pessoas singulares e coletivas, assegurando o pagamento consecutivo equivalente ao direito do cidadão?

Frente a atual pandemia causada pelo SARS-COV-2, a quarentena, distanciamento social e isolamento demonstraram ser muito eficazes no Brasil e também em outros países como na China e Itália, pelo fato de proporcionarem a diminuição na taxa de reprodução e no tempo de duplicação da doença. Contudo, existe uma divergência na literatura em relação à utilização dos termos para tratar esta medida. Quarentena, isolamento social, auto-isolamento e distanciamento social muitas vezes, são mencionados com o mesmo objetivo. Assim, para sanar este problema, o MS apresentou em sua página, uma definição para cada uma destas estratégicas, de modo a amenizar as possíveis confusões ${ }^{33}$.

Desta forma, acredita-se que as atitudes adotadas pelo MS no Brasil e descritas neste trabalho estão de acordo com as ações tomadas pelos demais países, que enfrentaram a COVID-19 e que tiveram sucesso nos seus resultados. Entretanto, a subnotificação dos casos menos graves da doença são preocupantes? ${ }^{7}$.

\section{CONCLUSÃO}

As ações das autoridades brasileiras frentes a pandemia da COVID-19 no Brasil, foram listadas a fim de verificar a efetividade no combate da disseminação da doença.

Em resposta à pergunta norteadora da presente revisão, medidas não farmacológicas como isolamento social, quarentena e higienização das mãos, estão entre as principais recomendações feitas à população brasileira, devido à ausência de imunizações preventivas e de fármacos para tratamento. Com isso, percebe-se que as medidas tomadas pelo Brasil foram baseadas em condutas que foram eficazes em outras emergências de saúde pública no país, e que apresentaram características clínicas e epidemiológicas semelhantes ao agente etiológico da atual pandemia, contribuindo assim, para a redução da contaminação e transmissão do vírus. 
1. Croda JHR, Garcia LP. Resposta imediata da Vigilância em Saúde à epidemia da COVID-19. Epidemiologia e Serviços de Saúde [Internet]. 2020 Mar 23 [cited 2020 May 12];29(1) DOI http://dx.doi.org/10.5123/s1679-49742020000100021. Available from: https://www.scielo.br/scielo.php?script=sci_arttext\&pid=S2237-96222020000100100\&Ing=en\&nrm=iso\&tl$\mathrm{ng}=\mathrm{en}$

2. Queiroz NSF, Barros LL, Azevedo MFC, Oba J, Sobrado CW, Carlos AS, et al. Management of inflammatory bowel disease patients in the COVID-19 pandemic era: a Brazilian tertiary referral center guidance. Clinics (São Paulo) [Internet]. 2020 Apr 17 [cited 2020 May 12];75 DOI https://dx.doi.org/10.6061\%2Fclinics\%2F2020\%2Fe1909. Available from: https://www.ncbi.nlm. nih.gov/pmc/articles/PMC7153358/.

3 Oliveira TC, Abranches MV, Lana RM. Food (in) security in Brazil in the context of the SARS-Cov-2 pandemic. Cad. Saude Publica [Internet]. 2020 Apr 06 [cited 2020 May 12];36(4) DOI https:// doi.org/10.1590/0102-311x00055220. Available from: https:// pubmed.ncbi.nlm.nih.gov/32267383/.

4. Oliveira WK, Duarte E, França GVA, Garcia LP. How Brazil can hold back COVID-19. Epidemiol. Serv. Saúde [Internet]. 2020 Apr 27 [cited 2020 May 12];29(2) DOI http:// dx.doi.org/10.5123/s1679-49742020000200023. Available from: https://www.scielo.br/scielo.php?script=sci_arttext\&pid=S2237-96222020000200200\&lng=pt\&nrm=iso\&tlng=en

5. Morales AJR, Gallego V, Antezana JPE, Méndez CA, Zambrano LI, Paredes CF, et al. COVID-19 in Latin America: The implications of the first confirmed case in Brazil. Travel Medicine and Infectious Disease [Internet]. 2020 Feb 28 [cited 2020 May 12]; DOI https://doi.org/10.1016/j.tmaid.2020.101613. Available from: https://www.sciencedirect.com/science/article/pii/ S1477893920300806?via\%3Dihub

6. Chen ATC, Moniz CMV, Júnior UR, Diz MDPE, Salvajoli JV, Vasconcelos KGMC, et al. How should health systems prepare for the evolving COVID-19 pandemic? Reflections from the perspective of a Tertiary Cancer Center. Clinics [Internet]. 2020 Apr 09 [cited 2020 May 12];75 DOI http://dx.doi.org/10.6061/clinics/2020/ e1864. Available from: https://www.scielo.br/scielo.php?pid=S1 807-59322020000100102\&script=sci_arttext\&tlng=en;

7. Rafael RMR, Neto M, Carvalho MMB, David HMSL, Acioli S, Faria MGA. Epidemiologia, políticas públicas e pandemia de COVID-19: o que esperar no Brasil?. Revista Enfermagem Uerj [Internet]. 2020 Apr 02 [cited 2020 May 12];28 DOI https:// doi.org/10.12957/reuerj.2020.49570. Available from: https:// www.e-publicacoes.uerj.br/index.php/enfermagemuerj/article/ view/49570

8. Ministério da Saúde BR. Sobre a doença: Como é transmitido [Internet]. [place unknown]; 2020 [cited 2020 May 12]. Available from: https://coronavirus.saude.gov.br/sobre-a-doenca\#sintomas

9. Croda J, Oliveira WK, Frutuoso RL, Mandetta LH, Silva DCB, Sousa JDB, et al. COVID-19 in Brazil: advantages of a socialized unified health system and preparation to contain cases. Revista da Sociedade Brasileira de Medicina Tropical [Internet]. 2020 Apr 03 [cited 2020 May 12];53 DOI 10.1590/0037-8682-01672020. Available from: https://doi.org/10.1590/0037-86820167-2020

10. Barradas BRC. Dez coisas que você deveria saber sobre o Qualis. RBPG [Internet]. $22^{\circ}$ de dezembro de 2016 [citado $12^{\circ}$ de maio de 2020];13(30). Disponível em: http://ojs.rbpg.capes.gov. br/index.php/rbpg/article/view/947

11. Fernandes EG, Santos JS, Sato HK. Outbreak investigation in cargo ship in times of COVID-19 crisis, Port of Santos, Brazil. Rev. Saúde Pública [Internet]. 2020 Mar 30 [cited 2020 May 12];54 DOI https://doi.org/10.11606/s1518-8787.2020054002461. Available from: https://pesquisa.bvsalud.org/portal/resource/pt/ biblio-1087486

12. Garcia LP, Duarte E. Intervenções não farmacológicas para o enfrentamento à epidemia da COVID-19 no Brasil. Epidemiologia e Serviços de Saúde [Internet]. 2020 Apr 09 [cited 2020 May 12];29(2) DOI https://doi.org/10.5123/s167949742020000200009. Available from: https://www.scielosp. org/article/ress/2020.v29n2/e2020222/

13. Lana RM, Coelho FC, Gomes MFC, Cruz OG, Bastos LS, Villela DAM, et al. Emergência do novo coronavírus (SARS-CoV-2) e o papel de uma vigilância nacional em saúde oportuna e efetiva. Cadernos de Saúde Pública [Internet]. 2020 Mar 13 [cited 2020 May 12];36 DOI https://doi.org/10.1590/0102-311x00019620. Available from: https://www.scielo.br/scielo.php?script=sci_arttext\&pid=S0102-311X2020000300301

14. Serdan TDA, Masi LN, Gorjao R, Curi TCP, Curi R, Hirabara SM. COVID-19 in Brazil: Historical cases, disease milestones, and estimated outbreak peak. Travel Medicine and Infectious Disease [Internet]. 2020 May 29 [cited 2020 May 12]; DOI https://doi. org/10.1016/j.tmaid.2020.101733. Available from: https://www. sciencedirect.com/science/article/pii/S147789392030212X?via\%3Dihub

15. Barreto ML, Barros AJD, Carvalho MS, Codeço CT, Hallal PRC, Medronho RA, et al. What is urgent and necessary to inform policies to deal with the COVID-19 pandemic in Brazil?. Revista Brasileira de Epidemiologia [Internet]. 2020 Apr 22 [cited 2020 May 12];23 DOI https://doi.org/10.1590/1980-549720200032. Available from: https://pubmed.ncbi.nlm.nih.gov/32321004/.

16. Castro R, Luz PM, Wakimoto MD, Veloso VG, Grinsztejn B, Perazzo H. COVID-19: a meta-analysis of diagnostic test accuracy of commercial assays registered in Brazil. The Brazilian Journal of INFECTIOUS DISEASES [Internet]. 2020 [cited 2020 May 12];2(24) DOI http://dx.doi.org/10.1016/j. bjid.2020.04.003. Available from: https://www.bjid.org.br/ en-COVID-19-meta-analysis-diagnostic-test-accuracy-articulo-S1413867020300295

17. Bastos LS, Niquini RP, Lana RM, Villela DAM, Cruz OG, Coelho FC, et al. COVID-19 and hospitalizations for SARI in Brazil: a comparison up to the 12th epidemiological week of 2020. Cad. Saúde Pública [Internet]. 2020 Apr 22 [cited 2020 May 12];36(4) 


\section{REFERÊNCIAS}

DOI https://doi.org/10.1590/0102-311x00070120. Available from: https://pesquisa.bvsalud.org/portal/resource/\%20es/mdl32321075

18. Lavinsky J, Kosugi EM, Batista E, Roithmann R, Dolci E, Ribeiro TK, et al. An update on COVID-19 for the otorhinolaryngologist - a Brazilian Association of Otolaryngology and Cervicofacial Surgery (ABORL-CCF) Position Statement. Braz J Otorhinolaryngol [Internet]. 2020 [cited 2020 May 12];86(3) DOI https://doi. org/10.1016/j.bjorl.2020.04.002. Available from: https://pesquisa.bvsalud.org/portal/resource/pt/mdl-32371055

19. Correia MITD, Ramos RF, Bahten LCV. The surgeons and the COVID-19 pandemic. Rev. Col. Bras. Cir [Internet]. 2020 Mar 30 [cited 2020 May 12];47 DOI https://doi.org/10.1590/01006991e-20202536. Available from: https://pubmed.ncbi.nlm.nih. gov/32236295/.

20. Brito LGO, Ribeiro PA, Filho ALS. How Brazil Is Dealing with COVID-19 Pandemic Arrival Regarding Elective Gynecological Surgeries. The Journal of Minimally Invasive Gynecology [Internet]. 2020 Apr 24 [cited 2020 May 12]; DOI https://doi. org/10.1016/j.jmig.2020.04.028. Available from: https://www jmig.org/article/S1553-4650(20)30216-8/fulltext

21. Lorenz C, Azevedo TS, Neto FC. COVID-19 and dengue fever: A dangerous combination for the health system in Brazil. The Journal of Minimally Invasive Gynecology [Internet]. 2020 [cited 2020 May 12];1(1) DOI 10.1016 / j.tmaid.2020.101659. Available from: https://www.sciencedirect.com/science/article/pii/ S1477893920301277?via\%3Dihub

22. Souza TS, Coelho EGA, Oliveira TRS, Santos JCS, Barros PBF. Ocorrência de febre amarela no Brasil: uma revisão integrativa d literatura (2014-2018). Revista Eletrônica Acervo Saúde [Internet]. 2019 Aug 13 [cited 2020 May 12];:1-10. DOI https://doi. org/10.25248/reas.e896.2019. Available from: https://acervomais.com.br/index.php/saude/article/view/896

23. Mizumoto K, Kagaya K, Zarebski A, Chowell G. Estimating the asymptomatic proportion of coronavirus disease 2019 (COVID-19) cases on board the Diamond Princess cruise ship, Yokohama, Japan, 2020 separator. Eurosurveillance [Internet]. 2020 [cited 2020 May 12];25(10) DOI https://doi.org/10.2807/15607917. ES.2020.25.10.2000180. Available from: https:// www.eurosurveillance.org/content/10.2807/1560-7917. ES.2020.25.10.2000180

24. Wang J, Wang Z. Strengths, Weaknesses, Opportunities and Threats (SWOT) Analysis of China's Prevention and Control Strategy for the COVID-19 Epidemic. International Journal of Environmental Research and Public Health [Internet]. 2020 [cited 2020 May 12];17(7) DOI https://doi.org/10.3390/ijerph17072235. Available from: https://www.mdpi.com/1660-4601/17/7/2235

25. Ministério da Saúde. Plano de Contingência Nacional para Infecção Humana pelo novo Coronavírus - COVID-19. Brasília: Centro de Operações de Emergências de Saúde Pública (COECOVID-19) [Internet]; 2020 [cited 2020 Mai 12]. Available from:

https://portalarquivos2.saude.gov.br/images/pdf/2020/fevereiro/13/plano-contingencia-coronavirus-COVID19.pdf
26. Ministério da Saúde BR. NOTA INFORMATIVA N³/2020-CGGAP/DESF/SAPS/MS [Internet]. Brasil; 2020 Apr 04 [cited 2020 May 12]. Available from: https://www.saude.gov.br/images/ pdf/2020/April/04/1586014047102-Nota-Informativa.pdf

27. Cimerman S, Chebado A, Cunha CA, Morales AJR. Deep impact of COVID-19 in the healthcare of Latin America: the case of Brazil. The Brazilian Journal of Infectious Diseases [Internet]. 2020 [cited 2020 May 12];24:93-95. DOI: 10.1016/j.bjid.2020.04.005. Available from: https://www. bjid.org.br/en-deep-impact-COVID-19-in-healthcare-articulo-S1413867020300325

28. Pan X, Ojcius DM, Gao T, Li Z, Pan C, Pan C. Lessons learned from the 2019-nCoV epidemic on prevention of future infectious diseases. Microbes and Infection [Internet]. 2020 [cited 2020 May 12];22(2) DOI https://doi.org/10.1016/j.micinf.2020.02.004. Available from: https://www.sciencedirect. com/science/article/abs/pii/S1286457920300320?via\%3Dihub

29. Adhikari SP, Meng S, Wu YJ, Mao YP, Ye RX, Wang QZ, et al. Epidemiology, causes, clinical manifestation and diagnosis, prevention and control of coronavirus disease (COVID-19) during the early outbreak period: a scoping review. Infectious Diseases of Poverty [Internet]. 2020 [cited 2020 May 12];29(9) DOI 10.1186/s40249-020-00646-x. Available from: https://www. ncbi.nlm.nih.gov/pmc/articles/PMC7079521/.

30. Sohrabi C, Alsafi Z, O'Neill N, Khan N, Kerwan A, Al-Jabir A, et al. World Health Organization declares global emergency: $A$ review of the 2019 novel coronavirus (COVID-19). International Journal of Surgery [Internet]. 2020 [cited 2020 May 12];76:7176. DOI https://doi.org/10.1016/j.ijsu.2020.02.034. Available from: https://www.sciencedirect.com/science/article/pii/ S1743919120301977

31. Ministério da Saúde BR. Brasil registra 71.886 casos de coronavírus e 5.017 mortes da doença [Internet]. [place unknown]; 2020 Apr 28 [revised 2020 May 29; cited 2020 May 12]. Available from: https://www.saude.gov.br/noticias/agenciasaude/46806-brasil-registra-71-886-casos-de-coronaviruse-5-017-mortes-da-doenca

32. Hung IFN, Lung KC, Tso EYK, Liu R, Chung TWH, Chu MY, et al. Triple combination of interferon beta- $1 \mathrm{~b}$, lopinavir-ritonavir, and ribavirin in the treatment of patients admitted to hospital with COVID-19: an open-label, randomised, phase 2 trial. The Lancet [Internet]. 2020 May 08 [cited 2020 May 12];395 DOI https:// doi.org/10.1016/S0140-6736(20)31042-4. Available from: https://www.thelancet.com/journals/lancet/article/PIIS01406736(20)31042-4/fulltext

33. Ministério da Saúde BR. Saúde regulamenta condições de isolamento e quarentena [Internet]. Brasília; 2020 Mar 13 [revised 2020 Mar 13; cited 2020 May 12]. Available from: https:// www.saude.gov.br/noticias/agencia-saude/46536-saude-regulamenta-condicoes-de-isolamento-e-quarentena\#: :tex$\mathrm{t}=$ "0\%20isolamento\%20não\%20é\%20obrigatório,velocidade\%20 de\%20transmissão\%20do\%20coronavírus. 